\title{
Improving governance arrangements in support of sustainable cities
}

\section{Ellen van Bueren, Ernst ten Heuvelhof}

Faculty of Technology, Policy and Management, Delft University of Technology, PO Box 5015, 2600 GA Delft, The Netherlands; e-mail: ellenb@tbm.tudelft.nl, e.f.tenheuvelhof@tbm.tudelft.nl Received 27 July 2003; in revised form 14 September 2004

\begin{abstract}
Governance to support sustainable development always seems to encounter the same difficulties. The chances of successful governance increase when governance arrangements are better tuned to the environment that it tries to change. However, a better fit leaves less room for change. Governance arrangements supporting sustainable development are more prone to failure, as they aim at changing that environment. Radical institutional change is at the core of sustainable development, but without the help of external factors, such as major crises like the oil crisis in the 1970s, the sense of urgency for such radical change is lacking, and incremental change seems to be the only road available. The authors explore how governance arrangements deal with this recurring barrier to institutional change. Their conclusion is that the more governance arrangements respect the institutional context in which they are used, the higher their quality. To speed up the incremental track, the design of governance arrangements should include positive incentives for actors to cooperate.
\end{abstract}

\section{Introduction: governance and institutional change}

The relationship between governance and institutional change is a complicated one. Governance arrangements aimed at institutional change meet resistance and are likely to fail because, for example, the arrangements lack support from key stakeholders. Recurring failure of policies and plans (for example, of the regulatory environmental regimes and the normative blueprint planning from the 1960s and 1970s) have had their impact on theories of public policy and planning, and these theories have increasingly recognized the need to take the institutional context into account (Alexander, 1992).

The growing attention paid to the institutional context is reflected in the word governance, which is used nowadays to mean processes of policymaking and decisionmaking: governance refers to the more cooperative processes of governing, policymaking, and decisionmaking, so different from the old hierarchical model in which state authorities exerted sovereign control over the groups and citizens that make up civil society (Mayntz, 2003). Governance emphasizes that policies are formulated and implemented in multiactor, networked environments, in which actors pursue different goals (Rhodes, 1997). The relationships between actors in these networked environments are characterized by interdependencies, and the actors need to cooperate to achieve their goals (De Bruijn and ten Heuvelhof, 2000). The interactions amongst actors who aim to address a policy problem take place in 'arenas' - virtual places where stakeholders interact and exchange information, knowledge, and points of view, and in which they try to achieve agreement on the way in which the policy problem should be addressed (Klijn and Koppenjan, 2000).

The institutional context in which governance arrangements are formulated and implemented thus consists of stable patterns of interaction amongst actors and the rules by which these interactions take place. These rules can be of a formal or informal character. Examples of formal rules are the constitution, contracts, legal procedures, and regulations; examples of informal rules are traditions, behavioral patterns, and social conventions. Institutions are shared by many actors and, by 
their acting in accordance with institutions, the institutions are confirmed and reconfirmed. Institutions are therefore often referred to as 'the rules of the game' (March and Olsen, 1989; Weimer, 1995). As in games, institutions influence decisionmaking to a large extent, but they do not determine the course and outcomes of the game (Ostrom, 1990).

The great advantage of institutions is that they bring structure into chaos and they make the world, including policy processes, more predictable; but at the same time, the reliability and predictability of institutions make them difficult to change (Hendriks, 1999). Within a stable institutional environment, actors formulate the governance arrangements by which they try to change some of the organizations, patterns, and practices: actors try to change the institutional environment, an environment that is resistant to change (Clay, 1994; Holm, 1995; Hood, 2002). From the point of view of this institutional rigidity, contingent governance design is to be preferred: to a certain degree, governance arrangements should match the institutional environment in which they are to have effect. Otherwise, the chances that they will fail are high (see, for example, Hajer, 1995; Weaver et al, 2000).

A complicating factor is that many of today's policy problems, such as sustainable urban development, are ill structured. They consist of multiple dimensions and causeand-effect chains which are complex and difficult to determine unambiguously. The problems are dealt with at different administrative levels, such as local, regional, and national or international levels, and there are different issues at stake that receive attention from actors from different networks. In sustainable urban development processes, for example, the actors involved belong to networks formed around issues such as housing, construction, planning, energy supply, and water management, and the problem is addressed in multiple arenas in which actors from different networks participate and in which the actors are guided by different rules for interaction. The heterogeneous character of the institutional environment of complex policy problems, with the multiple networks, interaction patterns, interdependencies, rules, arenas, etc, makes contingent governance design a difficult task, which is likely to end in highly incremental, piecemeal decisionmaking that will not result in groundbreaking changes.

In the Netherlands policies for sustainable urban development, as developed in the 1990s, have been based on the concept of governance and contingent design (Glasbergen, 1995). The basic idea was that governance arrangements were more likely to be successful when they were tuned to the environment, with its multiple actors and institutions, in which they were supposed to have effect. From the 1989 National Environmental Policy Plan (Ministry of Housing, Spatial Planning and the Environment, 1999) onwards, governance arrangements were therefore formulated in close cooperation with stakeholders, and institutional factors played an important role in governance design. Fifteen years later it is interesting to see whether these governance arrangements have contributed to institutional change and what factors in the governance design have contributed to the success or failure of these arrangements.

\section{The quality of governance for sustainable urban development}

In this paper we explore the complicated relationship between governance and institutional change within a rather elementary framework. The aim of the framework is that it should be able to identify the institutional changes to which a governance arrangement has contributed, and the factors in the design of the arrangement that have contributed to its success or failure.

The framework is constructed from different theories in governance, which evaluate governance from a process point of view and not from a substantive point of view, as is 
usually done in classic, goal-rational evaluations (Alexander, 1996). The choice of process criteria over substantive criteria can be explained by looking at the nature of the sustainable development concept. It is of a contested and ambiguous character, which implies that the concept consists of multiple issues and dimensions and that there are always competing perceptions on how it should be advanced (Rittel and Webber, 1973). This makes it impossible to prefer one set of substantive evaluation criteria to any other. Evaluation of governance arrangements from such a substantive point of view often leads to 'dialogues of the deaf': endless debates in which people fail to convince each other (Van Eeten, 1999). In addition, such analyses are not able to deal with the dynamics of the social environment in which governance takes place (De Bruijn and ten Heuvelhof, 2000).

In search of evaluative criteria, we therefore turn to theories that make use of process criteria to evaluate governance. Theories on network management and process management teach us that governance arrangements are successful when the different stakeholders are satisfied with the course and outcomes of the policy process (Teisman, 1995). This satisfaction is an indication that the arrangement has offered stakeholders, with their different and sometimes competing and conflicting perceptions, enough room to participate and to articulate and exchange their points of view, knowledge, and information (Klijn and Koppenjan, 2000). A second criterion for policy success can be found in the patterns of interaction. Changed interaction patterns are an indicator of institutional change: the interdependencies between actors have changed, and this may also lead to changes in the problem-solving space (Klijn and Koppenjan, 2000; Teisman, 1995).

There are two questions, however, that cannot be addressed by process-based evaluation criteria: how to distinguish sustainable from unsustainable outcomes; and how to achieve sustainable outcomes. A process-based approach to governance design and evaluation omits a substantive dimension for determining the sustainability of decisionmaking. Also, an action perspective that could help actors to develop actions by which they can advance their goals is absent. In theoretical debates about planning and decisionmaking, these flaws of a process approach to governance are recognized and are considered similar to the flaws of classic, rational theories on planning and decisionmaking: they are of a normative character and lack a descriptive and prescriptive dimension (Alexander, 1996; Blom-Hansen, 1997; Dowding, 1995; Marsh and Smith, 2001).

It is beyond the scope of this paper to solve this problem theoretically. As mentioned, we are not the first to signal this gap in process-based theories, and we are not the first to attempt to fill the gap. Most efforts in this direction aim at an integration of the rational and the communicative paradigm on which rational, substantive theories and process theories are, respectively, based (for example, Costanza et al, 2001; Rotmans et al, 2000; Sabatier and Jenkins-Smith, 1993).

In this paper, we apply a more pragmatic approach. Instead of developing an integrated theory, we use an analytical framework that incorporates substantive and action dimensions, in addition to the process dimension for which we already have identified two criteria. Especially useful to our exercise are theories that consider planning and decisionmaking from a learning perspective (for example, Argyris and Schön, 1978; Hall, 1993; Sabatier, 1987). Sustainable development, after all, can be considered as an ongoing learning process, in which actors from different networks and disciplinary backgrounds exchange perceptions; in these processes of interaction they can learn from and with each other about the substance of the problem in question and about the actions needed to address the problem. 
From a learning perspective, governance arrangements can be deemed successful when they have contributed to cognitive learning, the third criterion for our framework, when actors have collectively learned about the nature of sustainable urban development - when they have come to an improved and shared understanding of the causes and effects underlying the policy problem. A fourth and final indicator for governance success in the analytical framework, which represents the action dimension, is referred to as social learning; this considers the extent to which actors have learned about the actions that are needed to achieve sustainable urban development.

Together, these four factors help to nuance the results of a process evaluation of governance arrangements that focus simply on a match or mismatch of the arrangement with the institutional environment. These factors help to identify whether governance arrangements have resulted in institutional change that has contributed to sustainable urban development, and what factors account for the success or failure of these arrangements.

\section{Methodology: qualitative case-study research}

In this paper we analyze the extent to which two Netherlands governance arrangements have contributed to institutional change, and what factors have contributed to the success or failure of these arrangements. The two governance arrangements, each with two variants, were introduced in the 1990s to enhance sustainable urban development.

The first is called the spatial contours arrangement and is concerned with restricting urbanization of the countryside by drawing administrative borders, the so-called 'spatial contours', around the urban cores of municipalities. This instrument consists of two subarrangements: red contours for 'state-restricted areas', which are known for their top-down character and which seem to ignore the decisionmaking powers of decentralized governments in this field; and green contours for 'provincially restricted areas', in which the contours are the result of processes of interaction between stakeholders.

The second case is that of the packages for sustainable building which contain lists of dos and don'ts for sustainable building. The building sector was made responsible for designing and adhering to these lists, minimizing government intervention as much as possible. Also in this arrangement, two subarrangements can be identified. For the construction of residential and nonresidential buildings, and for infrastructures, packages have been developed in which the wishes and demands of the potential users were taken as the starting point. For urban planning, a package was developed based on an idea of what sustainable urban planning should be about; the institutional context within which these ideas should be realized was of lesser importance.

Both arrangements thus contain elements of traditional, rational approaches to planning and policymaking and of modern governance. The two approaches are theoretical constructions. In reality, governance arrangements are often inspired by both approaches, being the result of substantive policy ambitions of politicians and the wish to create support for these ambitions by offering stakeholders the opportunity to participate in the process of formulating and implementing the policy goals and means.

The cases in this paper were selected because they are governance arrangements for the enhancement of sustainable urban development, and have been influenced by the process approach that was very popular in the 1990s, but they contain more rational elements as well. They are expected to provide images of how the governance approach is capable of contributing to institutional change contributing to sustainable 
urban development, and how these arrangements manage to combine rational with communicative elements effectively.

Another reason for selecting these particular governance arrangements is of a more practical nature: we have studied them for other research assignments, and we therefore had much material available for the analyses that we wanted to perform-ranging from reports and documents to transcripts of interviews with key stakeholders. The results from the individual studies of these cases have been discussed with representatives of the key stakeholders involved.

In the following sections the arrangements are only briefly described, as they have previously been documented at length. ${ }^{(1)}$ Our emphasis here is on the analysis of the arrangements. After the description of the arrangements, they are evaluated by the four criteria of our framework. Each section ends with a table summarizing the analysis, and our conclusions are to what extent the arrangement has contributed to institutional change that enhances sustainable urban development.

\section{Case 1: the spatial contours arrangement}

Space is a scarce good in the Netherlands. In white papers on spatial planning, the Netherlands government sets out the spatial planning policies for the coming five to ten years. It is left to the provinces and the municipalities to implement these policies in their provincial and municipal spatial plans. The 1993 white paper, the VinexVierde Nota over de Ruimtelijke Ordening Extra (Ministry of Housing, Spatial Planning and the Environment, 1993) introduces policies to restrict urbanization of the countryside by concentrating new urban developments in or adjacent to already urbanized areas. The goals of these policies are threefold: (1) to protect the spatial and ecological values of the countryside; (2) to reduce the need for mobility; and (3) to improve support for urban facilities. The spatial contour is a new instrument introduced in the white paper to implement this policy. Other important instruments in this arrangement are nationally planned large-scale residential developments, the so-called Vinex locations, indicated on a map in the white paper; and a municipal quota for housing and business parks allocated by provincial government - an instrument that already existed. The spatial contours add a spatial dimension to this quota instrument; the quota should be realized within the contours.

The spatial contours are an administrative version of medieval city walls: red lines indicate the borders for urbanization. The contours have to be implemented by the provincial governments by drawing red lines around the urbanized cores of the municipalities on the maps of their provincial spatial plans. They have to do this for all municipalities that fall within the nationally restricted areas indicated on the map in the white paper. The red lines have to be tight, leaving municipalities just enough room for the dwellings and business parks allocated to them for the next ten to fifteen years. The national inspectorate for spatial planning, an enforcement agency of the Ministry of Housing, Spatial Planning and the Environment, has to approve the provincial plans of which these contours form part. Besides the 'national' contours, the white paper also indicates areas in which provincial governments should implement the contours. The main difference from the national contours is that here the provinces are free to choose the way they implement the contours, as long as they add a spatial dimension to their urbanization policies.

(1) The case study about the national packages for sustainable building is presented in Van Bueren et al (2001) and in Van Bueren and Van Keeken (2000). The spatial contours case study is described in detail in De Bruijn et al (1998) and in Van Bueren (1998). 
Although simple in design, the spatial contour instrument led to highly polarized debates during its implementation stage. Municipalities saw this instrument as an extra form of intervention by higher authorities in a decentralized policy area. Moreover, they were restricted in their own spatial developments in favor of the Vinex locations, which were situated in large municipalities and whose commercial success depended on there being sufficient demand for dwellings. Many of the municipalities confronted with the contours consisted of small villages in the countryside that already faced a housing shortage, which was forcing young people to move out of their home towns, and declining support for facilities such as shops and public transport. Instead of a debate on spatial quality, the drawing of the contours led to a dispute between national, provincial, and municipal authorities about decisionmaking powers and the problems of small villages that feared for their existence.

The provincial authorities were caught in the middle of these disputes. As implementers of the national policy, they had to deliver the contours in their provincial plans. These had to be approved by the national inspectorate for spatial planning, which is responsible for implementing national policies. Some provinces performed their task to the letter and became deeply involved in instrumental debates with the municipalities about the exact location of the red lines, sometimes even at the level of individual dwellings and premises. Other provinces claimed that this was not their concern, and they trusted the municipalities to make proposals for the contours. Some provinces and municipalities refused to collaborate at all, claiming that this policy did not contribute to the spatial quality of the urban environment; however, the Minister of Housing, Spatial Planning and the Environment finally forced them to comply.

The provincial contours offered more room for constructive debates about spatial quality. Municipalities were allowed to draw the contours in collaboration with other municipalities. In some cases, this led to detailed studies of the spatial quality of the urban cores, their surroundings, and their future potential. Plans were developed that were based on spatial quality, as intended by the governance arrangement. Although the contours in these plans might not be as rigid and tight as expected, the plans took account of the transition area between towns and countryside. Drawing the contours from a regional point of view allowed solutions for the problems of small villages to be sought on a regional level, which offered more opportunities than did problem solving on an individual level.

We now analyze the success of the spatial contours arrangement for the four variables in our framework.

\section{Satisfactory policy outcomes}

The national contours did not lead to satisfactory policy outcomes. Although the contours were drawn on the provincial maps, it is not expected that they will contribute to the formal policy goals within the intended period of ten to fifteen years. Many of the municipalities had already planned developments for housing and business parks, plans for which the legal procedures had already been started and which could not be withdrawn. As a result, the contours could not be drawn as tightly as was intended in the white paper. The contours are not likely to contribute to spatial and ecological values in the countryside in the next few years. The contribution to the other two policy goals can also be questioned. These policy goals were formulated from the point of view of the Vinex locations and the municipalities where they are built. The small municipalities point to the increasing dependence of their inhabitants on cars to reach the facilities in the cities. The link with the support for urban facilities is rather indirect, with many other interfering variables, and it is very difficult to claim any contribution of the contours arrangement to this goal yet. 
In some cases the provincial contours have led to more satisfying policy outcomes. The provinces and municipalities had the freedom to implement the contours in such a way that they reached the best trade-off between their own interests and the environmental interests, that is, the ecological values of the landscape.

The spatial contours were presented and formulated from the point of view of the large municipalities where the Vinex locations were planned, and not from the point of view of the small municipalities that faced the restrictions resulting from the contours. These small municipalities perceived the contours as a red border that threatened their existence by diminishing the opportunities to build the new dwellings needed to support facilities.

The provincial contours left more room for interpretation, which the provincial and municipal authorities used to reframe the contours in line with their interests and goals. The provincial contours acknowledged the authority of municipalities for their spatial policies. Decentralizing the responsibility for drawing the contours made great demands on the self-organizing capacities of local authorities. The interdependencies between local authorities turned out to provide sufficient checks and balances to make sure that the package deals were in line with the formal policy goals of the spatial and housing policies.

\section{Cognitive learning about the nature of sustainable development}

In theory, the Ministry of Housing, Spatial Planning and the Environment, which issued the white paper, assumed that drawing the contours would lead to a debate within municipalities about the values of the landscape in the urban cores and the surroundings. This debate would not only form the basis for fixing the contours, but would also provide incentives to reflect on the ways in which the space was used. For instance, the land scarcity created by the contours would lead to a revitalization of derelict places in urban cores rather than to the building of new residential areas in the countryside.

However, these learning processes did not take place in the case of the national contours, and the contours were discussed from a rather instrumentalist point of view. Municipalities and provincial authorities, hardly willing to collaborate, were drawing lines on the map without much reflection. There was no incentive to stimulate discussions about spatial and ecological qualities. Neither the white paper nor the ministry provided criteria or guidelines for drawing the contours, even though municipal and provincial authorities explicitly asked for guidelines. Furthermore, the spatial contours were not clearly linked to other issues about spatial quality in the urban environment, which had a prominent place on the political agenda at the time. There was no learning process about spatial and ecological qualities. Instead, the municipalities questioned and contested the national contours and the policy goals they should contribute to, sometimes in coalition with the provinces, and the contours became nothing but red lines on maps. In addition, the contours were established for a period of ten to fifteen years. Considering that the time span for local politicians is four years at most, the contours offer many municipal governments enough space for urban developments in the period that they are in office. They experience no incentive to learn about spatial qualities or to use the space within the contours efficiently; they assume that their successors will find ways to deal with the lack of space or will succeed in obtaining more space.

The freedom offered by the provincial contours offered more opportunities for cognitive learning processes. Municipalities, often in collaboration with other municipalities in the region, explored the present and potential ecological and spatial values in the urban landscape and the surrounding countryside, as well as the way in which 
a symbiosis between the two could be established or improved. In these cases the contours were integrated into plans and developments, instead of being just red lines on a map.

\section{Changed patterns of interaction}

The implementation of the contours depended on the collaboration of municipalities and provinces. Legal procedures for spatial planning, in particular, require clear coordination between the different government levels. Provincial and municipal authorities are free to develop spatial plans, as long as they do not interfere with the strategies set out in the national white papers. The Minister of Housing, Spatial Planning and the Environment has legal powers to force the provincial and municipal authorities to implement national policies. In the case of the contours, the minister sometimes had to threaten provinces with these powers.

However, especially in the Netherlands 'polder model', in which policymaking is based on negotiated consensus, the top-down character of the contours, which were forced upon provincial and municipal authorities, was not greeted with enthusiasm: it was felt to be another intervention by central and provincial government into their decentralized decisionmaking powers. In some municipalities and provinces the contours initially resulted in the start of substantive debates in which connection was sought with many other issues of land-use, housing, and urban planning, involving interactions between different experts, municipal departments, and interest groups; but these debates were aborted when the ministry emphasized that the contours should be interpreted literally. After this proclamation, interactions continued along the same lines, but on a very formal basis, characterized by a lack of trust on both sides. The national government and some provincial governments assumed that, without strict control, the municipalities would claim contours that were too wide. The municipal governments and some provincial governments felt that the contours ignored and even contributed to the problems which the small communities were facing. It was this mutual mistrust in particular that started the self-fulfilling prophecy, and the actors displayed the behavior that they expected of each other.

The drawing of the provincial contours resulted in changes in patterns of interaction on a regional scale. In order to determine the contours, neighboring municipalities set up working groups in which they studied the existing and potential qualities in the region with regard to a multitude of issues, such as landscape, ecological values, water management, demographic developments, housing, transport, and facilities. The provincial contours became institutionally embedded in the intermunicipal cooperative agreements that already existed, and they were laid down in the provincial spatial plans; these changed patterns of interaction are likely to continue in the future.

\section{Social learning about the implementation of sustainable development}

As we have seen above, the national contours in particular led to strategic learning processes in which municipalities tried to make the contours as wide as possible and the provincial and national government tried to make them as narrow as possible. Local authorities claimed that the red lines left them insufficient room to meet demands for urban activities like housing, offices, and recreation. According to the national spatial and housing policies, problems like these should be solved on a regional level. Making the red lines the problem of individual local authorities, and sometimes even of individual urban cores, enabled the municipalities to reframe the debate on a local level. The debate was no longer about spatial quality. It was reframed in terms of the survival of local communities, a debate in which municipalities put much effort into claiming more space than was needed and into finding ways to avoid the restrictions of the red contours. 
Table 1. Explanation of the success or failure of the spatial contours arrangement.

\begin{tabular}{lll}
\hline $\begin{array}{l}\text { Success } \\
\text { or failure }\end{array} \quad$ Case & Result & $\begin{array}{l}\text { Explanation (match or mismatch } \\
\text { between governance arrangement and } \\
\text { institutional context) }\end{array}$ \\
\hline
\end{tabular}

\begin{tabular}{lll}
\hline Satisfactory & national & no-outcomes \\
policy & contours & frustrating for all \\
outcomes & & actors
\end{tabular}

Arrangement ignores

policy contours

outcomes

frustrating for all decentralized decisionmaking powers;

autonomous developments (planning

procedures already started);

goals and interests of actors to be governed.

provincial yes-outcomes

contours are satisfactory

to all actors

$\begin{array}{lll}\begin{array}{l}\text { Cognitive } \\ \text { learning about } \\ \text { the nature }\end{array} & \begin{array}{l}\text { national } \\ \text { contours }\end{array} & \begin{array}{l}\text { no-the rigid } \\ \text { definition of } \\ \text { of sustainable }\end{array} \\ \begin{array}{l}\text { contours left } \\ \text { no ron }\end{array} & & \begin{array}{l}\text { noom for } \\ \text { learning }\end{array}\end{array}$

development

Changed patterns of interaction

Social learnabout implementation of sustainable urban development national contours contours yes-actors have learned about present and future spatial qualities in their region

national contours

provincial contours

no-interactions were restricted to formal interactions

yes-spatial quality has become an issue on the agenda of regional arenas

no-strategic learning by all actors

yes-room for package deals
Arrangement

makes use of existing institutions and the self-organizing capacity of regional actors;

adds a new dimension to existing interaction patterns;

offers actors to be governed

opportunities to couple contours with other goals and interests;

relies on interdependencies preventing misuse.

Actors contest the policy theory on which the arrangement was based. The policy theory:

does not match competing policy theories, adhered to by the actors to be governed; lacks convincing, substantive arguments; lacks explicit links with other policy issues;

does not match the time span of local politicians.

Arrangement offers actors to be governed opportunities to reframe the contours and couple them to other goals, interests, and decisionmaking processes.

Interactions were soon restricted to the formal channels that already existed and were characterized by distrust.

\section{Arrangement}

has resulted in new arenas in which the regional contours were discussed;

has been anchored in existing institutional structures.

Implementation arrangement is characterized by mistrust and denial of interdependencies; instrumentalist approach to the contours by all parties;

lack of incentives to comply with arrangement; making a collective problem a problem of individual municipalities.

Arrangement offers a wider problemsolving space, which enables the actors to be governed to tune the implementation of the contours to other policy issues. 
Social learning did take place in the case of the provincial contours. Implementing the contours on a regional level made the area in which spatial and environmental qualities should be established much larger. It enabled actors to seek win-win situations between spatial qualities in the urban areas and the countryside. In some cases the package deals were extended to other issues of local concern, which required coordination on a regional level. The regional approach of the contours offered opportunities to deal with the contours in existing arenas in the region, which will also provide an arena for implementing the policy goals of the contours in the future.

\section{Summary and conclusions}

Table 1 summarizes the successes and failures of the spatial contours, and the most important institutional explanations. Based on this overview, the following conclusions can be drawn about the contour arrangement. The most important question is, of course, that of whether the arrangement contributed to sustainable institutional change. For the national contour arrangement the answer is no. The process was frustrating to all actors, and did not lead to any learning or changes in interactions; the minister in office has proposed the complete abolition of the national contours in the near future. The provincial contours present a more positive story. In the provinces studied, sustainable institutional change took place: new and durable patterns of interaction emerged, with an explicit focus on sustainable regional development.

The provincial contour arrangement succeeded in mobilizing regional forces that were interested in sharing and developing knowledge about sustainable regional development, whereas the national contour arrangement discouraged initiatives of municipalities in this direction. The provincial contour arrangement offered provinces and municipalities the opportunity to mold the provincial contours to an arrangement in which policy goals in adjacent fields could be integrated, and which could become part of the existing institutional structures. The national contours did not offer this possibility of matching the arrangement with the institutional context. Instead, the national contour arrangement ignored the decentralization of powers with respect to local planning - and was contested because of this.

\section{Case 2: the national packages for sustainable building}

The Netherlands national packages for sustainable building are packages of measures containing dos and don'ts for sustainable building. The goals of the packages were twofold: (1) to harmonize and disseminate the knowledge on sustainable building amongst all actors in the building sector; and (2) to put an end to the diversity in the sustainable building requirements formulated by municipalities, that is, the harmonization of decentralized policies (Ministry ofHousing, Spatial Planning and the Environment, 1995).

The idea for the packages was laid down in the 1995 white paper on sustainable building by the Ministry of Housing, Spatial Planning and the Environment (1995). This white paper launched many policies and activities to put sustainable building on the agenda of Netherlands policymakers, practitioners, researchers, and, of course, the building sector. To create support and commitment for the ideas in the white paper, it appealed to the self-organizing capacity of the building sector. Government intervention and involvement were to be reduced to a minimum.

The building sector, whose interests were at stake in these packages, was happy to carry out this task. The existing checklists formulated by the municipalities or environmental organizations endangered their interests; the checklists tended to ban products and practices without clear scientific evidence. There was also great variety in municipal policies, which resulted in high interaction costs. The building sector had to negotiate with each municipality separately about the local sustainable building policies. 
The building sector used its existing institutional structures, such as networks, organizations, and procedures, to set up the national packages. This resulted in four national packages - one for each subsector. The packages were developed in a relatively short time. The package for residential buildings was published in 1996 (SBR, 1996); for nonresidential buildings in 1998 (SBR, 1998); and for urban planning (Nationaal Dubo Centrum, 1999) and for infrastructures in 1999 (CROW et al, 1999). Each of the packages was developed by a platform consisting of umbrella organizations, private and public, within the building sector. The packages for residential and nonresidential buildings, and for infrastructures, were developed within stronger institutional structures than was the case for the package for urban planning. Urban planning is a profession rather than a sector, and as such is not as strongly dominated by industrial and commercial interests as are the building sectors: this resulted in a package that differed from the other three.

The packages for residential and nonresidential buildings and for infrastructures are widely known and used (Ministry of Housing, Spatial Planning and the Environment, 1999). They have become a sort of a sustainable building standard in the Netherlands. These packages have similar structures and have been developed in similar processes; they are therefore grouped together in the following analysis. They present measures in a simple and clear format; they use lifecycle analysis (LCA) as the scientific method to prove the sustainability of measures; they classify the measures according to the sustainability issues to which they contribute; and they give a cost indication of the measures. Decisions within the platform (for example, about the proposal and revision of measures) should be based on unanimity. The measures are presented on paper and on CD-ROM; and the CD-ROM especially directs users quickly to the measures that are relevant for the project they are working on. The package for urban planning is well known, but not widely used. It is presented as a book, with lots of text and pictures, and pays a lot of attention to the pros and cons of measures and the interference between the measures.

The status of the packages is diffuse. Although initiated and approved of by the Ministry of Housing, Spatial Planning and the Environment, they were formulated by the building sector. The packages are applied on a voluntary basis, although various national, provincial, and local government organizations encourage the use of the packages.

Determination of the success or failure of the national packages according to the variables of the analytical framework gave the following results.

\section{Satisfactory policy outcomes}

The building sector has succeeded in harmonizing knowledge about sustainable building and in disseminating this knowledge amongst the target groups within a short period of time. This outcome is satisfactory both for the ministry and for the building sector. The packages for residential and nonresidential buildings and for infrastructures are widely known and used. The urban planning package is also widely known, and the actors involved in formulating the package are also satisfied with the result. However, this package is hardly used, despite special workshops on how to use it.

The building sector saved a lot of time by using existing institutional structures to establish the packages. The interaction costs were limited to setting up a new arena for interaction and designing decisionmaking rules, but it was possible to copy most of these institutions from existing arenas and rules. The actors involved in setting up the urban planning package could not fall back on existing institutions that were familiar to all. The actors involved in setting up this package thus had to invest a lot of time and effort in the development of an arena for interaction. The absence of strong institutionalized 
structures was again felt when the urban planning package was ready for use: a natural distribution chain was lacking. In addition, the incentive structure to use this package was less strong than in the other three cases. Group pressure was lacking and by the time it appeared, in 1999, sustainable building was less prominent on the political agenda than it had been in 1996 and 1997 when the packages for residential buildings and commercial buildings were published.

The package for infrastructure, which also appeared in 1999, was less troubled by the lack of public and political attention as the target group consisted of actors who were well organized and it was dominated by a number of large constructors and by the Directorate-General of Public Works and Water Management - the ministerial department that is responsible for the construction, maintenance, and exploitation of public works in the Netherlands and is the main principal in assigning projects in this field.

\section{Cognitive learning about the nature of sustainable development}

The packages aimed to diffuse rather than to develop knowledge on sustainable building. The cognitive learning processes were therefore confined to actors who were unfamiliar with sustainable building. The unanimous decisionmaking rules resulted in a preference for best practical means over best available means. The rules for revising the measures discourage innovation. Only those sustainability measures that can be expressed in an LCA score and in costs qualify for the packages. Revisions of measures are therefore mostly incremental, such as a small increase in the required energy performance of materials.

The packages do not stimulate users to learn about the effects on sustainability of applying the measures from the packages. For example, in the first years of the package for residential buildings, a building was deemed sustainable if measures were applied that added up to a certain surplus in costs, regardless of the environmental effects accomplished by applying the measures. The feedback information presented in the packages just helps users to determine what measures they have used and to what sustainability issues each measure contributes. The packages do not tell users how to assess the sustainability gains resulting from adopting a variety of measures from the packages.

The urban planning package contains more information about interference with other measures and about the environmental gains of the measures. However, it is presented in an inaccessible way, without clear cost information, and, as a result, most actors do not use the book at all.

The packages thus did not lead to cognitive learning about sustainable urban development. The packages for residential and nonresidential buildings resulted in instrumental use of the knowledge on which the measures in the packages was based, whereas the lessons in the urban planning package were not accepted by its potential users.

In the cases of the packages for residential and nonresidential buildings, this can be ascribed to the use of the existing institutional structures to develop the packages. Although the packages were developed in specially created arenas, interactions in these arenas were dominated by the rules that dominate the other arenas in this sector. These rules are strongly developed and have been established to serve interests other than sustainable development. The Netherlands building sector is a very closed sector, and its institutions take care of its financial well-being-sometimes even to the extent that building projects are allocated by the building sector itself instead of the commissioning party, as turned out to be the case during a parliamentary inquiry in 2002. The institutions are based on shared commercial interests, rather 
than on shared interests in sustainable development. This has had effects on the decisionmaking rules in the packages platforms. They are directed more towards protecting commercial interests than towards supporting sustainable building. LCA, for example, is a method that can be manipulated because the results depend heavily on the assumptions used. The sustainability ambitions of the measures were based on the extra costs compared with the use of traditional materials and practices, without considering future benefits. And the requirement for unanimity of votes made certain that only those measures which were acceptable to all, that is, those measures with moderate sustainability ambitions which were easy to apply without much disruption of the building process, were adopted.

The package for urban planning was also developed within an arena that was especially created for this purpose but, unlike the arenas for the other packages, this arena could not make use of strongly developed rules for interaction and decisionmaking. This created the opportunity to focus strongly on sustainability ambitions, instead of on the protection of interests, but it led to a lengthy process in which not much attention was paid to the representation of interests and to the needs and wishes of potential users. There were no clear criteria to decide on the content of the package and the link with financial implications of the suggested measures was limited, whereas cost is a dominant factor in decisionmaking in building projects.

The absence of existing institutions in the case of the urban planning package did create the opportunity to focus on sustainable urban planning. However, when complete, the package could not command the same authority as the other packages, and a distribution channel was lacking. Also, although there was no coordination with the other packages, the urban planning package made use of the same jargon-words such as 'package' and 'measures', words that were in contradiction with the professional freedom of the urban planner who considers each assignment as a unique one to which no blueprint applies. By presenting the many lessons on sustainable urban planning in the form of a package with measures, the package could not count on the sympathy of its potential users.

\section{Changed patterns of interaction}

The packages for residential and nonresidential buildings and for infrastructures were developed in arenas that were specially created. However, existing patterns of interactions and interdependencies amongst actors in the building and construction sector formed the basis for these arenas. The advantage of these new arenas was that they offered actors the opportunity to focus the discussion on sustainable building and on the design and implementation of the packages, and thus this did lead to some new interactions that had not taken place before. For example, it created arenas in which industry, research institutes, and governmental and nongovernmental organizations could discuss sustainable building. Because only umbrella organizations were allowed to participate, it also contributed to a further structuring of the industry: industries that wanted to participate in the debate to protect their interests had to join one of the participating organizations.

The creation of new arenas to develop the packages led to very goal-directed processes in which new patterns of interaction were formed. However, the interactions in these arenas were strongly influenced by the existing interdependencies amongst actors. The strict rules for interaction and decisionmaking in the building and construction industry also dominated the interactions in the newly created arenas, and commercial interests influenced decisionmaking heavily. 
Table 2. Explanation of the success or failure of the national packages for sustainable building.

\begin{tabular}{|c|c|c|c|}
\hline $\begin{array}{l}\text { Success } \\
\text { or failure }\end{array}$ & Case & Result & $\begin{array}{l}\text { Explanation (match or mismatch } \\
\text { between governance arrangement and } \\
\text { institutional context) }\end{array}$ \\
\hline
\end{tabular}

\section{Satisfactory}

policy

outcomes

packages for
residential
and
nonresidential
buildings and
infrastructures
urban
planning
package

yes - packages

created

sustainable

building

standards that

are widely used

no-no

harmonization

and dissemina-

tion of

knowledge

\section{Cognitive}

learning about

the nature of

sustainable

urban

development packages for residential

and

nonresidential

buildings and

infrastructures no-diffusion of existing

knowledge, but no development of knowledge urban

planning

package

\section{Changed} patterns of interaction packages for residential and nonresidential buildings and infrastructures

urban planning package no-new arena was created but durability of arena is questionable
Arrangement made use of existing institutions to establish and distribute the packages, which reduced the interaction costs and led to fast decisionmaking processes.

Arrangement required creation of a new arena, but

this resulted in high interaction costs; the arena still had to earn authority among its members, and its products were not easily accepted.

Strict and unanimous decisionmaking rules

created consensus on the state of the art of sustainable building;

were procedures which had a weak link with the policy content;

created high entry barriers for sustainable building innovations, which are not based on LCA;

have led to the absence of feedback loops within the packages, which would enable the users to learn about sustainability.

Open debate within the platform has led to

low entry barriers for innovative ideas on sustainable urban planning;

ambiguous criteria for admittance of dos and don'ts;

attention to synergies and interferences between dos and don'ts; long decisionmaking process.

Interactions were restricted to existing networks and arenas

in which decisionmaking is dominated by interests other than sustainable urban development;

in which actors are not likely to be confronted with new perceptions on sustainable urban development.

The arena is a single-issue arena and its existence is likely to depend on the use of the packages; the place of sustainable urban development on the political agenda. 
Table 2 (continued).

\begin{tabular}{|c|c|c|c|}
\hline $\begin{array}{l}\text { Success } \\
\text { or failure }\end{array}$ & Case & Result & $\begin{array}{l}\text { Explanation (match or mismatch } \\
\text { between governance arrangement and } \\
\text { institutional context) }\end{array}$ \\
\hline
\end{tabular}

\begin{tabular}{llll}
\hline $\begin{array}{l}\text { Social learning } \\
\text { about } \\
\text { implementation } \\
\text { of sustainable } \\
\text { urban } \\
\text { development }\end{array}$ & $\begin{array}{l}\text { packages for } \\
\text { residential } \\
\text { and } \\
\text { nonresidential } \\
\text { buildings and } \\
\text { infrastructures }\end{array}$ & $\begin{array}{l}\text { no-especially } \\
\text { strategic learning } \\
\text { by actors }\end{array}$ & $\begin{array}{l}\text { The decisionmaking rules reward } \\
\text { instrumental use of the packages and } \\
\text { strategic learning. }\end{array}$ \\
& $\begin{array}{l}\text { urban } \\
\text { planning } \\
\text { package }\end{array}$ & $\begin{array}{l}\text { yes-the package } \\
\text { offers lessons on } \\
\text { this in theory, } \\
\text { but these lessons } \\
\text { are not applied }\end{array}$ & $\begin{array}{l}\text { Package pays attention to fitting } \\
\text { sustainable urban planning into existing } \\
\text { decisionmaking processes, but lacks a } \\
\text { clear connection with some important } \\
\text { existing decisionmaking criteria, such as } \\
\text { the financial implications of sustainable } \\
\text { urban planning; its holistic approach } \\
\text { makes it difficult for actors to implement. }\end{array}$ \\
& & &
\end{tabular}

${ }^{\text {a }} \mathrm{LCA}$ - lifecycle analysis.

Although interaction patterns have changed, the assumption that continuation of these interactions provides opportunities for learning is not valid in this case. The high entry barriers and the strict decisionmaking rules within the arenas reduce the chance of innovative ideas or perceptions on sustainable building gaining ground in these platforms. In 2004, the arenas in which the packages are updated and revised still exist, but the changes are of an incremental nature, aimed at a piecemeal tightening of the measures and at improving the usability of the packages by adding new functionalities in the software.

The package on sustainable urban planning led to the creation of an entirely new arena that did not come out of existing structures. Actors participated out of interest in the issue of sustainable urban planning, and because they felt they could make a contribution to the issue. Only the umbrella organizations, such as the association of town and country planners and the association of architects, felt the need to participate because of the interests that they represented. Together, the participating actors had to determine the scope and goal of the package and the measures it would contain. There were no clear rules for decisionmaking. Actors who did not support the idea of such a package with measures for sustainable urban planning did not participate, and the actors who did participate, like the associations mentioned, did not have the power to ensure that the package was used nor could they provide incentives to members to use the package. In the case of the urban planning package new interactions were created, but these interactions were not institutionalized. After the creation of the package the interactions did not continue.

Interactions between the arenas in which the different packages were developed and revised were limited to cases of double membership of some of the participants. The content and format of only two of the packages - for residential and for nonresidential buildings - were tuned to each other to some degree. This was because the developments of these packages were prepared by the same consultancy firm and the negotiations were chaired by the same research institute. Coupling between the substance and format with the other packages was restricted to the accidental participation of the same actor in more than one arena. The result is that the packages, each addressing different spatial scales, do not present a coherent vision on sustainable urban development, and some of the measures in the different packages are even in contradiction with each other. 


\section{Social learning about implementing sustainable urban development}

Actors especially learned strategically. They used the opportunity to frame the sustainable development concept in accordance with their interests. On the level of the development of the packages, they learned how to get their product or process a 'sustainability' label. On the level of the implementation of the packages, they learned how to give their building project a 'sustainable' label with a minimum of cost and effort. Incentives to future learning processes about sustainable urban development were limited. Because of the procedure for revision of the packages, changes in the packages will only be incremental, that is, measures will be modified, added, or removed. The decisionmaking rules thus reward strategic behavior.

The improvements in the user interface of the packages are especially aimed at making it easier to integrate the measures in the planning process. However, the result is that users are even less aware of the rationale behind the measures, and they are stimulated to use the packages in an instrumental way, without much reflection.

A lack of coordination between the packages is also seen in the implementation of the measures. The lack of coordination between the measures in the different packages prevents integrated design of the urban environment. There is no identification of interference among the measures or contradictions between the packages.

The package for urban planning pays more attention to social learning. Specific chapters are dedicated to the integration of the package in urban planning processes. However, these learning processes remain theoretical because of the limited number of users of the package.

\section{Summary and conclusions}

Table 2 summarizes the analysis of the national packages for sustainable building. Based on this overview, we can answer the question of whether the arrangement has resulted in institutional changes that contribute to sustainable urban development. At first sight, one would be inclined to answer this question positively for the packages for residential and nonresidential buildings and for infrastructures. After all, the packages have resulted in the creation of new arenas that still form a place to exchange perceptions on sustainable building in the different sectors, and the packages are widely used in building practice. On second sight, however, the new arenas have not led to any change in the interdependencies amongst actors in these sectors. Also, the packages have not led to a greater knowledge of sustainable building amongst their users, and the institutionalization of the packages in building practice seems to block rather than stimulate innovation in this field.

What seems to have happened is that the building sector has successfully captured the concept of sustainable development into packages that they consider to be acceptable. By making the packages highly contingent to the institutional context in which they are supposed to have effect the arrangement managed to get the support from the actors whose behavior it aimed to change, but the changes were of such an incremental and incidental nature that there were no resulting institutional changes to facilitate further developments in the field of sustainable building and sustainable urban development.

Also, the package for sustainable urban planning did not result in institutional change. Although actors involved in developing the package succeeded in developing knowledge on sustainable urban planning, they did not succeed in disseminating this knowledge. They overtly focused on the content of the package, emphasizing the importance of the message that they wanted to bring, and they did not pay much attention to the audience and its characteristics, such as the strong professional codes that make urban planners insusceptible to lessons in the form of generally applicable principles and measures. 


\section{Conclusions}

The case studies clearly show the dilemma central to this issue: the tension between governance and institutional change. With the national contours, central government aimed for radical changes by pursuing a strategy in which substantive views on how municipalities can contribute to sustainable urban development were forced upon stakeholders, thereby ignoring existing patterns of interactions and interdependencies between actors. Instead of sustainable urban development, this strategy contributed to strategic actor behavior and undesirable outcomes. The provincial contours resulted in more positive conclusions: by giving stakeholders the opportunity to tune the meaning and form of the arrangement to their own goals, interests, and institutions, the contours came to be based on a mixture of substantive and process criteria.

The national packages for sustainable building followed a contingent approach, leaving the design and implementation of the governance arrangement to the building sector. In the case of the packages developed for subsectors which are characterized by strong institutional structures, the results are arrangements that outstandingly achieved the formal policy goals, but which failed to contribute to learning processes about sustainable urban development. Institutional change did take place, but the changes make only a limited contribution to sustainable urban development. With the urban planning package, actors participating in the development of the package aimed for more radical changes, but ignored the institutional environment in which these changes should materialize and the package could not realize its ambitions.

The cases show two recurring strategies in governance design that explain the success or failure of the governance arrangements. The first concerns making use of existing institutional structures. To improve the institutional fit of the arrangement with its environment, it is important that actors or stakeholders in this institutional environment have the opportunity to tune the arrangement to this environment. After all, they know best what this environment looks like and what rules and relationships should be respected. In addition, this contributes to the efficiency of the arrangement by saving on the costs required to establish new patterns of interactions and rules for decisionmaking, and to the effectiveness of the arrangement by making the actors responsible for the arrangement produced.

The second strategy accounting for the success or failure of governance arrangements is the extent to which actors have the opportunity to reframe the arrangements. Reframing the arrangement provides actors with the opportunity to couple the policy goals to their own goals and interests, and to tune the arrangement to other decisionmaking processes. In this way, use can be made of the interdependent relationships between actors; actors often depend on each other on multiple issues, in multiple policy arenas, and at multiple moments in time, which gives them the opportunity to create package deals and thus transform zero-sum games into win-win situations.

In combination, these strategies can contribute to the success of governance arrangements. But even when governance arrangements are designed according to these strategies, they are likely to lead to incremental rather than radical changes. For example, the arrangement of the packages for residential and nonresidential buildings and for infrastructures followed a strategy aimed at an institutional match and which gave actors the opportunity to reframe the arrangement.

Of the case studies in this paper, that of the provincial contours arrangement seems to offer the best mix of these strategies. Provinces force municipalities to draw contours, but leave the organization and actual framing of the contours to the municipalities themselves. The municipalities, who in many cases already cooperated with other municipalities in their region on other issues of regional concern, used these arenas to discuss and draw the contours. This allowed the municipalities to present the 
contours as part of an integrated plan which addressed the problems of the region from several points of view, such as spatial planning, ecological development, and housing. This forced the municipalities to set the priorities for the sustainable development of their region themselves, and reduced the risks that they would make excessive claims on one of the issues addressed in the plan. By making the contours part of the integrated plan, the municipalities also committed themselves to continued interactions, decisionmaking, and innovation on this point, which increases the chances of more radical changes in the long term.

The inclusion of incentives in the design of governance arrangements may increase the likelihood of more radical institutional change resulting from the arrangement. In the case of the provincial contours, the following incentives were part of the design.

(a) Reward compliance, that is, on the issue of the contours or on another issue.

(b) Benchmark the proposals of the regions. Some of the plans were presented and promoted by the provincial authorities as 'best practice'.

(c) Safeguard continuation of the development and implementation of the contours by coupling them to other decisionmaking processes.

(d) Stimulate innovative ideas on the contours. This reduces the risk that spatial quality, the value promoted by the contour arrangement, will be exchanged for other values to which the contours are coupled.

(e) Put pressure on the decisionmaking process. The municipalities were free to suggest plans for the contours themselves within a limited amount of time. If they exceeded this time limit, the provincial authorities would draw the contours for the municipalities.

Together, strategies and incentives such as those mentioned in this section are able to keep alive the learning processes about sustainable urban development initiated by governance arrangements. They can do so without ending as satisfactory processes with unsustainable outcomes, or in dialogues of the deaf, in which parties involved all claim to pursue sustainable, but different, goals, resulting in unsatisfying and stagnated decisionmaking processes.

To conclude, there is one incentive in the provincial contour arrangement that we have not mentioned: the presence of the national contour arrangement. It is possible that the rigid red contour regime might have provided a strong incentive for actors to develop and implement the provincial contours as intended by national government and to refrain from strategic behaviour. The potential threat, where strategic behavior by municipalities falling under the provincial contour arrangement could be 'punished' for strategic behavior by making their land part of the national contour arrangement, perhaps created a strong incentive for actors to cooperate.

This brings us back to policy practice in which governance design is often based on a mixture of substantive, rational, theories of planning and decisionmaking and of communicative, process-oriented theories. The contour arrangement shows that a combined design may contribute to sustainable institutional change. It would be worthwhile to explore the potential of such a strategy in future empirical research, especially because the strategy seems to answer the needs of policymakers who want to aim for substantive, ambitious, goals while respecting the institutional environment as well-a combination that is also increasingly asked for by citizens, who call for visionary politicians who take their needs into account.

Acknowledgement. This publication is the result of work carried out at the Delft Center for Sustainable Urban Areas. 


\section{References}

Alexander E R, 1992 Approaches to Planning: Introducing Current Planning Theories, Concepts and Issues (Gordon and Breach, Yverdon, Switzerland)

Alexander E R, 1996, "After rationality: towards a contingency theory for planning", in Explorations in Planning Theory Eds S J Mandelbaum, L Mazza, R W Burchell (Center for Urban Policy Research, Rutgers, The State University of New Jersey, New Brunswick, NJ) pp $45-64$

Argyris C, Schön D A, 1978 Organizational Learning: Theory of Action Perspective (Addison-Wesley, Reading, MA)

Blom-Hansen J, 1997, “A new 'institutional' perspective on policy networks" Public Administration $75669-693$

Clay J A, 1994, "Public - institutional processes: beyond conventional wisdom about management processes" Administration and Society $26236-251$

Costanza R, Low B S, Ostrom E, Wilson J A, 2001, "Ecosystems and human systems: a framework for exploring the linkages", in Institutions, Ecosystems and Sustainability Eds R Costanza, B S Low, E Ostrom, J A Wilson (Lewis Publishers, Boca Raton, FL) pp 3-20

CROW, CUR, Nationaal Dubo Centrum, 1999 Nationaal Pakket Duurzaam Bouwen GWW [National package for sustainable building in civil engineering] CROW, Galvanistraat, Ede, $6716 \mathrm{AE}$

De Bruijn J A, ten Heuvelhof E F, 2000 Networks and Decision Making (Lemma, Utrecht)

De Bruijn J A, Van Bueren E M, ten Heuvelhof E F, 1998 Grenzen aan Contouren [Bordering contours] (Delft University of Technology, Delft)

Dowding K, 1995, "Model or metaphor? A critical review of the policy network approach" Political Studies $\mathbf{4 3} 136$ - 158

Glasbergen P, 1995 Managing Environmental Disputes: Network Management as an Alternative (Kluwer, Dordrecht)

Hajer M A, 1995 The Politics of Environmental Discourse: Ecological Modernization and the Policy Process (Oxford University Press, Oxford)

Hall P, 1993, "Policy paradigms, social learning and the state" Comparative Politics 23 275-296

Hendriks F, 1999 Public Policy and Political Institutions: The Role of Culture in Traffic Policy (Edward Elgar, Cheltenham, Glos)

Holm P, 1995, "The dynamics of institutionalization: transformation processes in Norwegian fisheries" Administrative Science Quarterly 40398 - 422

Hood C, 2002, "Control, bargains, and cheating: the politics of public-service reform" Journal of Public Administration Research and Theory 12309 - 332

Klign E H, Koppenjan J F M, 2000, "Public management and policy networks" Public Management: An International Journal of Research and Theory 2(2) 135 - 158

March J G, Olsen J P, 1989 Rediscovering Institutions: The Organizational Basis of Politics (The Free Press, New York)

Marsh D, Smith M J, 2001, "There is more than one way to do political science: on different ways to study policy networks" Political Studies $49528-541$

Mayntz R, 2003, "From government to governance: political steering in modern societies", presented at Summer Academy on IPP, Wuerzburg, 7-11 September, http://www.ioew.de/ governance/english/veranstaltungen/Summer_Academies/SuA2Mayntz.pdf

Ministry of Housing, Spatial Planning and the Environment, The Hague 1989 Nationaal Milieubeleidsplan [National Environmental Policy Plan]

1993 Vierde Nota over de Ruimtelijke Ordening Extra, deel 4: Planologische Kernbeslissing

Nationaal Ruimtelijk [Fourth national policy document on spatial planning extra, part 4:

key planning decision for a national spatial strategy]

1995 Plan van Aanpak Duurzaam Bouwen. Investeren in de Toekomst [Action plan for sustainable building: investing in the future]

1999 Monitoring Duurzaam Bouwen, Resultaten Plannen van Aanpak 1995 - 1999 [Monitoring sustainable building: results of the 1995 - 1999 action plans]

Nationaal Dubo Centrum, 1999 Nationaal Pakket Duurzame Stedebouw [National package for sustainable urban planning] Nationaal Dubo Centrum, Pastbus 29046, 3001 GA Rotterdam

Ostrom E, 1990 Governing the Commons: The Evolution of Institutions for Collective Action (Cambridge University Press, Cambridge)

Rhodes R A W, 1997 Understanding Governance: Policy Networks, Governance, Reflexivity and Accountability (Open University Press, Milton Keynes, Bucks) 
Rittel H J W, Webber M M, 1973, "Dilemmas in a general theory of planning" Policy Sciences 4 $155-169$

Rotmans J, Van Asselt M, Vellinga P, 2000, "An integrated planning tool for sustainable cities" Environmental Impact Assessment Review $20265-276$

Sabatier P A, 1987, "Knowledge, policy-oriented learning and policy change, an advocacy coalition framework" Knowledge: Creation, Diffusion, Utilization 8(4) 649-692

Sabatier P A, Jenkins-Smith H C (Eds), 1993 Policy Change and Learning: An Advocacy Coalition Approach (Westview Press, Boulder, CO)

SBR, 1996 Nationaal Pakket Duurzaam Bouwen Woningbouw: Nieuwbouw en Beheer [National package for sustainable housing: new constructions and housing management] Stichting Bouwresearch, Kruisplein 25, 3014 DB, Rotterdam

SBR, 1998 Nationaal Pakket Duurzaam Bouwen Utiliteitsbouw: Nieuwbouw en Beheer [National package for sustainable building of nondomestic buildings: new constructions and management] Stichting Bouwresearch, Kruisplein 25, 3014 DB, Rotterdam

Teisman G R, 1995 Complexe Besluitvorming: een Pluricentrisch Perspectief op Besluitvorming over Ruimtelijke Investeringen [Complex decisionmaking: a pluricentric perspective on decisionmaking about spatial investments] (Vuga, The Hague)

Van Bueren E M, 1998, "Contouren en Ruimtelijke Kwaliteit" [Contours and spatial quality] Stedebouw en ruimtelijke Ordening $538-43$

Van Bueren E M, Van Keeken E P H, 2000, "The Netherlands national packages for sustainable building, a first step towards a sustainable built environment", in Proceedings International Conference Sustainable Building 2000, Maastricht 22 - 25 October Eds C Boonstra, R Rovers, S Pauwels (Aeneas, Best) pp 414-418

Van Bueren E M, Van Keeken E P H, Canters K J, 2001 De Nationale Pakketten Nader Bekeken. Duurzaam Bouwen Nu en in de Toekomst [A closer look at the national packages: sustainable building today and in the future] DIOC-DGO De Ecologische Stad, Technical University of Delft, Delft

Van Eeten M, 1999 Dialogues of the Deaf: Defining New Agendas for Environmental Deadlocks (Eburon, Delft)

Weaver P, Jansen L, Van Grootveld G, Van Spiegel E, Vergragt P, 2000 Sustainable Technology Development (Greenleaf Publishing, Sheffield)

Weimer D L, 1995, "Institutional design: overview", in Institutional Design Ed. D L Weimer (Kluwer, Dordrecht) pp $1-16$ 